\title{
INFLUENCIA DE CULTURAS DE INVERNO SOBRE O RENDIMENTO DE GRÃOS DE SOJA CULTIVADA EM SISTEMAS DE ROTAÇÃO DE CULTURAS ${ }^{1}$
}

\author{
INFLUENCE OF WINTER CROPS ON SOYBEAN YIELD IN CROP ROTATION SYSTEMS
}

\author{
Henrique Pereira dos Santos ${ }^{2}$ Julio Cesar Barreneche Lhamby ${ }^{3}$
}

\section{RESUMO}

\begin{abstract}
Durante nove anos, avaliou-se o efeito de diferentes culturas antecessoras sobre o rendimento de grãos e sobre a estatura de plantas de soja, na EMBRAPA-Centro Nacional de Pesquisa de Trigo (CNPT), em Passo Fundo, RS. Os tratamentos consistiram em sete sistemas de rotação de culturas, e a soja foi semeada em sucessão à aveia branca, à aveia preta, ao linho e ao trigo. Em 1990, foram adicionadas duas parcelas, uma para completar o sistema II e outra para pousio de inverno antecedendo a soja (sistema VII). As culturas de inverno foram estabelecidas com preparo convencional de solo, e as de verão, em plantio direto. $O$ delineamento experimental foi blocos ao acaso, com três repetições, e parcelas com área útil de $30 \mathrm{~m}^{2}$. A soja cultivada após linho, na média do período de 1987 a 1989, nos sistemas IV e VI, apresentou menor estatura de plantas e menor rendimento de grãos. Nos períodos de 1990 a 1992 e de 1993 a 1995, não houve diferenças significativas entre tipo de cultura antecessora e rendimento de grãos. A soja cultivada após aveia branca, após aveia preta ou após trigo pode ser incluída, sem prejuízo, nos diferentes sistemas estudados.
\end{abstract}

Palavras-chave: sucessão de culturas, rendimento de grãos, estatura de plantas, aveia branca, aveia preta, linho, trigo.

\section{SUMMARY}

Different preceding crops on the yield and height of soybean plants was assessed during nine years at EMBRAPACentro Nacional de Pesquisa de Trigo (CNPT), in Passo Fundo, RS, Brazil. The treatments consisted of seven crop systems, and soybean was sown in succession to white oat, black oat, flax, and wheat. Two plots were added in 1990; one to complement system II and the other as winter fallow preceding soybean (system VII). Winter crops were set up using conventional soil preparation, and summer crops were sown under no-tillage. An experimental design of blocks at random, with three replications and plots

\begin{abstract}
totalling $30 m^{2}$, was used. The grown soybean after flax, in the mean of the period 1987 to 1989, in systems IV and VI showed lower plant on height and lower yield. No significant differences were found on the evoluated preceding crops on the yield over the periods 1990 to 1992 and 1993 to 1995. The grown soybean after white oat, black oat or wheat may be included in the different systems studied without any adverse effect.
\end{abstract}

Key words: crop succession, yield, plant height, white oat, black oat, flax, wheat.

\section{INTRODUÇÃO}

A soja é hoje o principal produto agrícola de exportação do Brasil, que é o segundo maior produtor e exportador mundial, superado apenas pelos Estados Unidos (CARUSO, 1996). Na safra 1997/98, a produção de soja ultrapassou 31,5 milhões de toneladas, havendo condições para esse número crescer de forma substancial nos próximos anos.

Em termos de grande propriedade, a soja é a espécie mais cultivada no país. Tem apresentado, em algumas regiões do Brasil, problemas relacionados ao manejo de solo e ao ataque de doenças e pragas, que estão afetando a sua produtividade (REUNIẪO, 1997). Sistemas de manejo de solo, compatíveis com as características de clima, planta e tipo de solo da região sul do país, são imprescindíveis para minimizar o processo de sua degradação (REUNIÃO, 1997). Nesse contexto, o plantio direto constitui o sistema de manejo com maior potencial

\footnotetext{
${ }^{1}$ Trabalho realizado com recursos parciais da FAPERGS.

${ }^{2}$ Engenheiro Agrônomo, Doutor, EMBRAPA-Centro Nacional de Pesquisa de Trigo (CNPT), CP 451, 99001-970 Passo Fundo (RS). Bolsista CNPq. E-mail: hpsantos@cnpt.embrapa.br. Autor para correspondência.

${ }^{3}$ Engenheiro Agrônomo, Doutor, EMBRAPA-CNPT.
} 
para atender esse objetivo, pois, além de ser mais eficaz para o controle de erosão (BARKER \& WÜNSCHE, 1977) e de ser mais econômico (DENARDIN \& KOCHHANN, 1993), contribui de forma decisiva para a melhoria dos aspectos físicos, químicos e biológicos do solo (MUZILLI, 1985) e para a redução dos custos de produção (WÜNSCHE \& TOMASINI, 1978).

O planejamento da sequiência de espécies dentro de um programa de rotação de culturas deve considerar, além do potencial de rentabilidade dessa seqüência, a suscetibilidade de cada cultura à infestação de pragas, de plantas daninhas e de doenças, a disponibilidade de equipamentos para o manejo das culturas e de resíduos vegetais (SANTOS et al., 1993); o histórico e o estado atual da lavoura, atentando para os aspectos de fertilidade do solo e de exigência nutricional das plantas (SOCIEDADE, 1995).

No uso da rotação de culturas sob plantio direto, os restos vegetais das diferentes espécies usadas são deixados na superfície do solo após a colheita. Nessa forma de deposição, os resíduos vegetais decompõem-se mais lentamente do que quando são incorporados ao solo pelas operações de preparo do mesmo (ROMAN \& VELLOSO, 1993).

$\mathrm{O}$ rendimento de grãos e a estatura de plantas de soja têm sido influenciados pelos resíduos de aveia branca, cevada, colza, linho e trigo (SANTOS et al., 1989). Nos trabalhos realizados em Guarapuava, PR, os menores rendimentos de grãos de soja, em sistemas de rotação de culturas para cereais de inverno, sob plantio direto, foram relacionados à inadequada cobertura de solo proporcionada pelo linho, em relação à aveia branca, à cevada ou ao trigo (SANTOS et al., 1997; SANTOS et al., 1998). SANTOS \& REIS (1991) verificaram efeitos negativos de resíduo de colza sobre soja, sob plantio direto, diminuindo a estatura de plantas e a produtividade. SANTOS \& TONET (1997), trabalhando com sistemas de produção de grãos com pastagens anuais de inverno e de verão, no ano de 1996, observaram efeito do resíduo da aveia branca para grãos sobre a soja, diminuindo estatura de plantas e rendimento de grãos, em comparação com resíduo de trigo.

O presente trabalho teve por objetivo avaliar o efeito da cultura anterior em diferentes sucessões de culturas sobre o rendimento de grãos e a estatura de plantas de soja.

\section{MATERIAL E MÉTODOS}

O trabalho foi conduzido na EMBRAPACentro Nacional de Pesquisa de Trigo (CNPT), município de Passo Fundo, RS, de 1987 a 1995, em
Latossolo Vermelho distrófico típico. A área experimental utilizanda foi cultivada, anteriormente, com lavouras de trigo, no inverno, e de soja, no verão.

Os tratamentos consistiram em sete sistemas de rotação para trigo: sistema I (trigo/soja); sistema II (trigo/soja, de 1987 a 1989, e trigo/soja e ervilhaca/milho ou sorgo, de 1990 a 1995); sistema III (trigo/soja, aveia preta ou aveia branca/soja e ervilhaca/milho ou sorgo); sistema IV (trigo/soja, aveia branca/soja, linho/soja e ervilhaca/milho, de 1987 a 1989, e trigo/soja, girassol ou aveia preta/soja, aveia branca/soja e ervilhaca/milho ou sorgo, de 1990 a 1995); sistema V (trigo/soja, trigo/soja, aveia preta ou aveia branca/soja e ervilhaca/milho ou sorgo); sistema VI (trigo/soja, trigo/soja, aveia branca/soja, linho/soja e ervilhaca/milho, de 1987 a 1989, e trigo/soja, trigo/soja, girassol ou aveia preta/soja, aveia branca/soja e ervilhaca/milho ou sorgo, de 1990 a 1995); e VII (pousio de inverno/soja, de 1990 a 1995) (Tabela 1). Em 1990, foram adicionadas duas parcelas por repetição, para completar o sistema II e para pousio de inverno antecedendo a soja (sistema VII) (Tabela 1). As culturas de inverno foram estabelecidas com preparo convencional de solo, e as de verão, em sistema plantio direto. As cultivares de soja usadas foram BR-4, de 1987 a 1992, e BR-16, de 1993 a 1995, semeadas na maioria dos anos numa única época, exceto em 1988 e 1995. A partir de 1990, nos sistemas de rotação III e $\mathrm{V}$, a sucessão aveia preta/soja foi substituída por aveia branca/soja. Nos sistemas de rotação IV e VI, entre 1990 e 1992, a sucessão linho/soja foi substituída por girassol e, a partir de 1993, este foi substituído pela sucessão aveia preta/soja. Nas safras 1990/91 e 1992/93, o milho não foi colhido, em decorrência da forte estiagem que ocorreu na região, sendo, posteriormente, substituído por sorgo.

Em maio de 1987, antes da instalação do experimento, houve correção da área experimental de acordo com os resultados da análise de solo, com a aplicação de 6,0t ha ${ }^{-1}$ (PRNT 90\%) de calcário. As amostragens de solo, para determinação dos níveis de nutrientes e do teor de matéria orgânica, foram realizadas, anualmente, em todas as parcelas, após a colheita das culturas de inverno. A adubação de manutenção foi baseada nos resultados da análise química da área.

A semeadura, o controle de plantas daninhas e o tratamento de sementes obedeceram à recomendação para a cultura de soja, e a colheita foi efetuada com colhedora especial de parcelas com $30 \mathrm{~m}^{2}$. Foi colhida toda a parcela.

A estatura de plantas foi determinada ao acaso em amostras de 20 plantas por parcela, uma semana antes da colheita. $\mathrm{O}$ rendimento de grãos foi 
Tabela 1 - Sistemas de rotação de culturas com espécies de inverno e de verão. Passo Fundo, RS.

\begin{tabular}{|c|c|c|c|c|c|c|c|c|c|}
\hline \multirow[t]{2}{*}{ Sistema de rotação } & \multicolumn{9}{|c|}{ Ano } \\
\hline & 1987 & 1988 & 1989 & 1990 & 1991 & 1992 & 1993 & 1994 & 1995 \\
\hline Sistema I & $\mathrm{T} / \mathrm{S}$ & $\mathrm{T} / \mathrm{S}$ & $\mathrm{T} / \mathrm{S}$ & $\mathrm{T} / \mathrm{S}$ & $\mathrm{T} / \mathrm{S}$ & $\mathrm{T} / \mathrm{S}$ & $\mathrm{T} / \mathrm{S}$ & $\mathrm{T} / \mathrm{S}$ & $\mathrm{T} / \mathrm{S}$ \\
\hline \multirow[t]{2}{*}{ Sistema II } & $\mathrm{T} / \mathrm{S}$ & $\mathrm{T} / \mathrm{S}$ & $\mathrm{T} / \mathrm{S}$ & $\mathrm{E} / \mathrm{M}$ & $\mathrm{T} / \mathrm{S}$ & $\mathrm{E} / \mathrm{M}$ & $\mathrm{T} / \mathrm{S}$ & E/So & $\mathrm{T} / \mathrm{S}$ \\
\hline & & & & $\mathrm{T} / \mathrm{S}$ & $\mathrm{E} / \mathrm{M}$ & $\mathrm{T} / \mathrm{S}$ & $\mathrm{E} / \mathrm{M}$ & $\mathrm{T} / \mathrm{S}$ & E/So \\
\hline \multirow[t]{3}{*}{ Sistema III } & $\mathrm{T} / \mathrm{S}$ & $\mathrm{Ap} / \mathrm{S}$ & $\mathrm{E} / \mathrm{M}$ & $\mathrm{T} / \mathrm{S}$ & $\mathrm{Ab} / \mathrm{S}$ & $\mathrm{E} / \mathrm{M}$ & $\mathrm{T} / \mathrm{S}$ & $\mathrm{Ab} / \mathrm{S}$ & E/So \\
\hline & $\mathrm{Ap} / \mathrm{S}$ & $\mathrm{E} / \mathrm{M}$ & $\mathrm{T} / \mathrm{S}$ & $\mathrm{Ab} / \mathrm{S}$ & $\mathrm{E} / \mathrm{M}$ & $\mathrm{T} / \mathrm{S}$ & $\mathrm{Ab} / \mathrm{S}$ & E/So & $\mathrm{T} / \mathrm{S}$ \\
\hline & $\mathrm{E} / \mathrm{M}$ & $\mathrm{T} / \mathrm{S}$ & Ap/S & $\mathrm{E} / \mathrm{M}$ & $\mathrm{T} / \mathrm{S}$ & $\mathrm{Ab} / \mathrm{S}$ & $\mathrm{E} / \mathrm{M}$ & $\mathrm{T} / \mathrm{S}$ & $\mathrm{Ab} / \mathrm{S}$ \\
\hline \multirow[t]{4}{*}{ Sistema IV } & $\mathrm{T} / \mathrm{S}$ & $\mathrm{Ab} / \mathrm{S}$ & $\mathrm{L} / \mathrm{S}$ & $\mathrm{E} / \mathrm{M}$ & $\mathrm{T} / \mathrm{S}$ & Gir & $\mathrm{Ab} / \mathrm{S}$ & E/So & $\mathrm{T} / \mathrm{S}$ \\
\hline & $\mathrm{Ab} / \mathrm{S}$ & $\mathrm{L} / \mathrm{S}$ & $\mathrm{E} / \mathrm{M}$ & $\mathrm{T} / \mathrm{S}$ & Gir & $\mathrm{Ab} / \mathrm{S}$ & $\mathrm{E} / \mathrm{M}$ & $\mathrm{T} / \mathrm{S}$ & $\mathrm{Ap} / \mathrm{S}$ \\
\hline & $\mathrm{L} / \mathrm{S}$ & $\mathrm{E} / \mathrm{M}$ & $\mathrm{T} / \mathrm{S}$ & Gir & $\mathrm{Ab} / \mathrm{S}$ & $\mathrm{E} / \mathrm{M}$ & $\mathrm{T} / \mathrm{S}$ & $\mathrm{Ap} / \mathrm{S}$ & $\mathrm{Ab} / \mathrm{s}$ \\
\hline & $\mathrm{E} / \mathrm{M}$ & $\mathrm{T} / \mathrm{S}$ & $\mathrm{Ab} / \mathrm{S}$ & $\mathrm{Ab} / \mathrm{S}$ & $\mathrm{E} / \mathrm{M}$ & $\mathrm{T} / \mathrm{S}$ & $\mathrm{Ap} / \mathrm{S}$ & $\mathrm{Ab} / \mathrm{S}$ & E/So \\
\hline \multirow[t]{4}{*}{ Sistema V } & $\mathrm{T} / \mathrm{S}$ & $\mathrm{T} / \mathrm{S}$ & $\mathrm{Ap} / \mathrm{S}$ & $\mathrm{E} / \mathrm{M}$ & $\mathrm{T} / \mathrm{S}$ & $\mathrm{T} / \mathrm{S}$ & $\mathrm{Ab} / \mathrm{S}$ & E/So & $\mathrm{T} / \mathrm{S}$ \\
\hline & $\mathrm{T} / \mathrm{S}$ & $\mathrm{Ap} / \mathrm{S}$ & $\mathrm{E} / \mathrm{M}$ & $\mathrm{T} / \mathrm{S}$ & $\mathrm{T} / \mathrm{S}$ & $\mathrm{Ab} / \mathrm{S}$ & $\mathrm{E} / \mathrm{M}$ & $\mathrm{T} / \mathrm{S}$ & $\mathrm{T} / \mathrm{S}$ \\
\hline & $\mathrm{Ap} / \mathrm{S}$ & $\mathrm{E} / \mathrm{M}$ & $\mathrm{T} / \mathrm{S}$ & $\mathrm{T} / \mathrm{S}$ & $\mathrm{Ab} / \mathrm{S}$ & $\mathrm{E} / \mathrm{M}$ & $\mathrm{T} / \mathrm{S}$ & $\mathrm{T} / \mathrm{S}$ & $\mathrm{Ab} / \mathrm{S}$ \\
\hline & $\mathrm{E} / \mathrm{M}$ & $\mathrm{T} / \mathrm{S}$ & $\mathrm{T} / \mathrm{S}$ & $\mathrm{Ab} / \mathrm{S}$ & $\mathrm{E} / \mathrm{M}$ & $\mathrm{T} / \mathrm{S}$ & $\mathrm{T} / \mathrm{S}$ & $\mathrm{Ab} / \mathrm{S}$ & E/So \\
\hline \multirow[t]{5}{*}{ Sistema VI } & $\mathrm{T} / \mathrm{S}$ & $\mathrm{T} / \mathrm{S}$ & $\mathrm{Ab} / \mathrm{S}$ & $\mathrm{Ab} / \mathrm{S}$ & $\mathrm{E} / \mathrm{M}$ & $\mathrm{T} / \mathrm{S}$ & $\mathrm{T} / \mathrm{S}$ & Ap/S & $\mathrm{Ab} / \mathrm{S}$ \\
\hline & $\mathrm{T} / \mathrm{S}$ & $\mathrm{Ab} / \mathrm{S}$ & $\mathrm{L} / \mathrm{S}$ & $\mathrm{E} / \mathrm{M}$ & $\mathrm{T} / \mathrm{S}$ & $\mathrm{T} / \mathrm{S}$ & $\mathrm{Ap} / \mathrm{S}$ & $\mathrm{Ab} / \mathrm{S}$ & E/So \\
\hline & $\mathrm{Ab} / \mathrm{S}$ & $\mathrm{L} / \mathrm{S}$ & $\mathrm{E} / \mathrm{M}$ & $\mathrm{T} / \mathrm{S}$ & $\mathrm{T} / \mathrm{S}$ & Gir & $\mathrm{Ab} / \mathrm{S}$ & E/So & $\mathrm{T} / \mathrm{S}$ \\
\hline & $\mathrm{L} / \mathrm{S}$ & $\mathrm{E} / \mathrm{M}$ & $\mathrm{T} / \mathrm{S}$ & $\mathrm{T} / \mathrm{S}$ & Gir & $\mathrm{Ab} / \mathrm{S}$ & $\mathrm{E} / \mathrm{M}$ & $\mathrm{T} / \mathrm{S}$ & $\mathrm{T} / \mathrm{S}$ \\
\hline & $\mathrm{E} / \mathrm{M}$ & $\mathrm{T} / \mathrm{S}$ & $\mathrm{T} / \mathrm{S}$ & Gir & $\mathrm{Ab} / \mathrm{S}$ & $\mathrm{E} / \mathrm{M}$ & $\mathrm{T} / \mathrm{S}$ & $\mathrm{T} / \mathrm{S}$ & $\mathrm{Ap} / \mathrm{S}$ \\
\hline Sistema VII & & & & $\mathrm{P} / \mathrm{S}$ & $\mathrm{P} / \mathrm{S}$ & $\mathrm{P} / \mathrm{S}$ & $\mathrm{P} / \mathrm{S}$ & $\mathrm{P} / \mathrm{S}$ & $\mathrm{P} / \mathrm{S}$ \\
\hline
\end{tabular}

$\mathrm{Ab}=$ aveia branca; $\mathrm{Ap}=$ aveia preta $\mathrm{E}=$ ervilhaca; $\mathrm{Gir}=$ girassol; $\mathrm{L}=$ linho; $\mathrm{M}=$ milho, $\mathrm{P}=$ pousio; $\mathrm{S}=$ soja; So = Sorgo; e $\mathrm{T}=$ trigo.

determinado a partir da colheita de toda a parcela, sendo corrigido para $13 \%$ de umidade.

$\mathrm{O}$ delineamento experimental foi de blocos ao acaso, com três repetições. Foi efetuada a análise de variância da estatura de plantas e do rendimento de grãos de soja (dentro de cada ano e na média conjunta dos anos, 1987 a 1989, 1990 a 1992 e 1993 a 1995). A análise de variância das médias foi aplicada a esses três períodos, devido às alterações efetuadas nos sistemas III, IV, V e VI, a partir de 1990. Considerou-se o efeito de tratamento (diferentes restevas de inverno) como fixo, e o efeito do ano, como aleatório. As médias foram comparadas entre si pelo teste de Duncan, em nível de 5\% de probabilidade de erro.

\section{RESULTADOS E DISCUSSÃO}

Os resultados serão apresentados em três períodos (1987 a 1989, 1990 a 1992 e 1993 a 1995), devido às modificações que ocorreram no experimento (sistemas III, IV, V e VI), a partir de 1990. O rendimento de grãos (1987 a 1989, 1990 a 1992 e
1993 a 1995) e a estatura de plantas de soja (1987 a 1989) foram significativamente influenciados pelo fator ano, indicando que essas variáveis foram afetadas pelas variações climáticas ocorridas entre os anos. Resultados similares foram obtidos por SANTOS et al. (1989 e 1998) e por SANTOS \& REIS (1991).

Nesses períodos de estudo e após as avaliações, não foram detectadas diferenças significativas entre as médias conjuntas para os componentes de rendimento (número de legumes, número de grãos e peso de grãos por planta), população final de plantas, peso de 1.000 grãos e altura de inserção dos primeiros legumes de soja, razão pela qual os mesmos não foram expressos em tabelas. Isso também foi válido para a estatura de plantas de 1990 a1992 e de 1993 a 1995. Os componentes de rendimento não têm sido influenciados pela resteva das espécies de inverno aqui avaliadas (SANTOS $\boldsymbol{e t}$ al., 1991) ou, quando isso se manifesta, não têm alterado 0 rendimento de grãos (SANTOS \& REIS, 1990). Esse fato ocorre porque a soja tende a compensar as possíveis falhas de estabelecimento da cultura que possam manifestar-se de um ano para outro, ramificando mais ou aproveitando melhor seu florescimento, que ocorre em etapas.

Os resultados da estatura de plantas (de 1987 a 1989) e do rendimento de grãos (de 1987 a 1989, de 1990 a 1992 e de 1993 a 1995), nesses períodos, podem ser verificados nas tabelas de 2 a 5 . Para a estatura de plantas (em 1988 e na média conjunta dos anos) (Tabela 2) e para o rendimento de grãos (1987 a 1989 e na média conjunta dos anos) (Tabela 3), observou-se que houve diferenças significativas em rendimento de grãos e em estatura de plantas, em virtude do tipo de cultura que antecedeu a soja (aveia branca, aveia preta, linho e trigo). Resultados semelhantes foram obtidos por SANTOS \& REIS (1991) e por SANTOS et al. (1998), com soja antecedida por aveia branca, cevada, colza, linho e trigo.

Na média conjunta dos anos (1987 a 1989), a soja cultivada após trigo, nos sistemas VI, III, V, IV e II e após aveia preta no sistema V, apresentou rendimento de grãos mais elevado (Tabela 3 ). Contudo, esses quatro últimos sistemas não foram estatisticamente diferentes de soja cultivada após 
Tabela 2 - Efeitos de culturas antecessoras na estatura de plantas de soja, cultivar BR 4, de 1987 a 1989. Passo Fundo, RS, 1999.

\begin{tabular}{|c|c|c|c|c|}
\hline \multirow{2}{*}{$\begin{array}{l}\text { Cultura } \\
\text { Antecessora }\end{array}$} & \multicolumn{3}{|c|}{ Ano } & \multirow[b]{2}{*}{ Média } \\
\hline & 1987 & 1988 & 1989 & \\
\hline \multirow{2}{*}{\multicolumn{5}{|c|}{ Sistema I }} \\
\hline $\begin{array}{l}\text { Sistema } 1 \\
\text { Soja após trigo }{ }^{1}\end{array}$ & & & & \\
\hline Soja após trigo ${ }^{1}$ & 97 & $98 \mathrm{cde}^{9}$ & 83 & $93 \mathrm{bc}$ \\
\hline Sistema II & & & & \\
\hline Soja após trigo ${ }^{2}$ & 101 & 101 bcde & 91 & $98 \mathrm{ab}$ \\
\hline Sistema III & & & & \\
\hline Soja após: trigo ${ }^{3}$ & 96 & 104 abcde & 92 & $97 \mathrm{ab}$ \\
\hline aveia preta & 102 & $108 a b c$ & 89 & $100 a b$ \\
\hline \multicolumn{5}{|l|}{ Sistema IV } \\
\hline Soja após: trigo ${ }^{4}$ & 102 & $109 \mathrm{ab}$ & 93 & $101 \mathrm{a}$ \\
\hline aveia branca & 96 & 104 abcde & 89 & $96 \mathrm{ab}$ \\
\hline linho & 94 & $86 \mathrm{~g}$ & 80 & $87 \mathrm{c}$ \\
\hline \multicolumn{5}{|l|}{ Sistema V } \\
\hline Soja após: trigo & 97 & $107 a b c$ & 83 & $96 \mathrm{ab}$ \\
\hline trigo $^{6}$ & 98 & $97 \mathrm{ef}$ & 85 & $93 \mathrm{abc}$ \\
\hline aveia preta & 102 & $111 \mathrm{a}$ & 85 & $99 \mathrm{ab}$ \\
\hline \multicolumn{5}{|l|}{ Sistema VI } \\
\hline Soja após: trigo ${ }^{7}$ & 97 & $107 \mathrm{abcd}$ & 94 & $99 \mathrm{ab}$ \\
\hline trigo $^{8}$ & 100 & $98 \mathrm{de}$ & 93 & $97 \mathrm{ab}$ \\
\hline aveia branca & 98 & $108 \mathrm{abc}$ & 77 & $94 \mathrm{ab}$ \\
\hline linho & 98 & $88 \mathrm{fg}$ & 73 & $86 \mathrm{c}$ \\
\hline Média & 98 & 102 & 86 & 96 \\
\hline C.V. (\%) & 6 & 6 & 9 & - \\
\hline F. tratamentos & $0,6 \mathrm{~ns}$ & $4.9^{*}$ & $2,1 \mathrm{~ns}$ & $2,7^{*}$ \\
\hline
\end{tabular}

${ }^{1}$ Monocultura de trigo. Sistema I.

${ }^{2}$ Monocultura de trigo até 1990 , depois trigo/soja ervilhaca milho. Sistema

${ }^{3}$ Trigo após aveia preta e ervilhaca. Sistema III.

${ }^{4}$ Trigo após aveia branca, linho e ervilhaca. Sistema IV.

${ }^{5}$ Trigo após aveia preta, ervilhaca e trigo. Sistema V.

${ }^{6}$ Trigo após trigo, aveia preta e ervilhaca. Sistema V.

${ }^{7}$ Trigo após aveia branca, linho, ervilhaca e trigo. Sistema VI.

${ }^{8}$ Trigo após trigo, aveia branca, linho e ervilhaca. Sistema VI.

${ }^{9}$ Médias seguidas da mesma letra, na coluna, não diferem entre si em $5 \%$ de probabilidade de erro, pelo teste de Duncan.

ns: não significativo; *: nível de significância de $5 \%$ de probabilidade de erro

trigo, no sistema I, e após aveia branca, nos sistemas IV e VI. A menor estatura de plantas e o menor rendimento de grãos de plantas de soja (Tabela 2) ocorreram na soja cultivada após linho, nos sistemas IV e VI. Esses resultados estão de acordo com os obtidos por SANTOS et al. (1997; 1998). Deve ser levado em consideração que esses sistemas foram similares significativamente para estatura de planta aos de soja cultivada após trigo, nos sistemas I e V, e para rendimento de grãos aos de soja cultivada após trigo, no sistema I, aveia preta, no sistema II, aveia branca, nos sistema IV, trigo e aveia preta, no sistema $\mathrm{V}$ e trigo e aveia branca, no sistema VI.

Nos casos de soja após linho, os menores valores para rendimento de grãos e para estatura de plantas da leguminosa estão relacionados diretamente às características da linácea. No trabalho conduzido por ROMAN (1990), o linho (1,2t ha- de palha) não proporcionou boa cobertura de solo, em relação à aveia branca $\left(7,4 \mathrm{tha}^{-1}\right)$, à aveia preta $(8,2 \mathrm{t}$ $\left.\mathrm{ha}^{-1}\right)$ ou ao trigo $\left(3,0 \mathrm{t} \mathrm{ha}^{-1}\right.$ de palha). Isso também foi
Tabela 3 - Efeitos de culturas antecessoras no rendimento de grãos de soja, cultivar BR 4, de 1987 a 1989. Passo Fundo, RS, 1999.

\begin{tabular}{|c|c|c|c|c|}
\hline \multirow{2}{*}{$\begin{array}{l}\text { Cultura } \\
\text { Antecessora }\end{array}$} & \multicolumn{3}{|c|}{ Ano } & \multirow[b]{2}{*}{ Média } \\
\hline & 1987 & 1988 & 1989 & \\
\hline & $\ldots \ldots$ & ........... $\mathrm{kg}$ & $\mathrm{ha}^{-1}$ & \\
\hline \multicolumn{5}{|l|}{ Sistema I } \\
\hline Soja após trigo ${ }^{1}$ & $1.595 b^{9}$ & $3.339 \mathrm{c}$ & 1.886 & $2.273 \mathrm{bcd}$ \\
\hline Sistema II & & & & \\
\hline Soja após trigo ${ }^{2}$ & $2.192 \mathrm{a}$ & $3.643 \mathrm{bc}$ & 1.862 & $2.566 \mathrm{abc}$ \\
\hline Sistema III & & & & \\
\hline Soja após: trigo ${ }^{3}$ & $1.695 \mathrm{~b}$ & $3.997 \mathrm{ab}$ & 2.760 & $2.817 \mathrm{a}$ \\
\hline aveia preta & $1.327 \mathrm{~b}$ & $3.263 \mathrm{c}$ & 1.863 & $2.151 \mathrm{~cd}$ \\
\hline \multicolumn{5}{|l|}{ Sistema IV } \\
\hline Soja após: trigo ${ }^{4}$ & $1.647 \mathrm{~b}$ & $3.937 \mathrm{ab}$ & 2.183 & $2.589 \mathrm{abc}$ \\
\hline aveia branca & $1.334 \mathrm{~b}$ & $3.442 \mathrm{bc}$ & 2.029 & $2.268 \mathrm{bcd}$ \\
\hline linho & $1.420 \mathrm{~b}$ & $2.570 \quad \mathrm{~d}$ & 1.908 & $1.966 \mathrm{~d}$ \\
\hline \multicolumn{5}{|l|}{ Sistema V } \\
\hline Soja após: trigo ${ }^{5}$ & $1.736 \mathrm{ab}$ & $3.986 \mathrm{ab}$ & 2.237 & $2.653 \mathrm{ab}$ \\
\hline trigo $^{6}$ & $1.433 \mathrm{~b}$ & $3.202 \mathrm{c}$ & 1.730 & $2.122 \mathrm{~cd}$ \\
\hline \multirow{2}{*}{\multicolumn{5}{|c|}{ Sistema VI }} \\
\hline & & & & \\
\hline Soja após: trigo ${ }^{7}$ & $1.757 \mathrm{ab}$ & $4.301 \mathrm{a}$ & 2.471 & $2.843 \mathrm{a}$ \\
\hline trigo $^{8}$ & $1.722 \mathrm{~b}$ & $3.108 \mathrm{~cd}$ & 2.400 & $2.410 \mathrm{abcd}$ \\
\hline aveia branca & $1.338 \mathrm{~b}$ & $3.604 \mathrm{bc}$ & 1.895 & $2.279 \mathrm{bcd}$ \\
\hline linho & $1.483 \mathrm{~b}$ & $2.553 \mathrm{~d}$ & 1.786 & $1.940 \quad \mathrm{~d}$ \\
\hline Média & 1.592 & 3.456 & 2.078 & 2.375 \\
\hline C.V. (\%) & 17 & 10 & 19 & - \\
\hline F. tratamentos & $2,2^{*}$ & $6,5^{*}$ & $1,6 \mathrm{~ns}$ & $3,1^{*}$ \\
\hline
\end{tabular}

${ }^{1}$ Monocultura de trigo. Sistema I.

${ }^{2}$ Monocultura de trigo até 1990 , depois trigo/soja ervilhaca milho. Sistema II.

Trigo após aveia preta e ervilhaca. Sistema III.

Trigo após aveia branca, linho e ervilhaca. Sistema IV

${ }^{5}$ Trigo após aveia preta, ervilhaca e trigo. Sistema V.

${ }^{6}$ Trigo após trigo, aveia preta e ervilhaca. Sistema V.

${ }^{7}$ Trigo após aveia branca, linho, ervilhaca e trigo. Sistema VI.

${ }^{8}$ Trigo após trigo, aveia branca, linho e ervilhaca. Sistema VI.

${ }^{9}$ Médias seguidas da mesma letra, na coluna, não diferem entre si em $5 \%$ de probabilidade de erro, pelo teste de Duncan.

ns: não significativo; *: nível de significância de $5 \%$ de probabilidade de erro.

observado, visualmente, no referido ensaio. A soja, na maioria dos anos em que foi antecedida pelo linho, nos sistemas IV e VI, levou mais tempo para germinar. A quantidade relativamente menor de palha de linho não foi adequada para o estabelecimento de soja (SANTOS $\boldsymbol{e t}$ al., 1997). Além disso, a soja após linho, em 1988, foi semeada por último (9/12/88), em relação à soja após aveia preta e trigo $(10 / 11 / 88)$ e após aveia branca (16/11/88). Isso pode ter concorrido para a diminuição da estatura de plantas, conforme verificou Santos et al. (1997).

Em 1990, 1991 e 1992, ocorreram diferenças significativas no rendimento de grãos, em função da cultura antecessora (aveia branca e trigo) (Tabela 4). Todavia, essa significância não se expressou para a média dos anos, porque os maiores rendimentos de grãos de soja variaram entre os tratamentos, de um ano para outro.

Nos anos de 1993 e de 1995, manifestaram-se diferenças significativas em rendimento de grãos de soja, em decorrência do tipo de cultura 
Tabela 4 - Efeitos de culturas antecessoras no rendimento de grãos de soja, cultivar BR 4, de 1990 a 1992. Passo Fundo, RS, 1999.

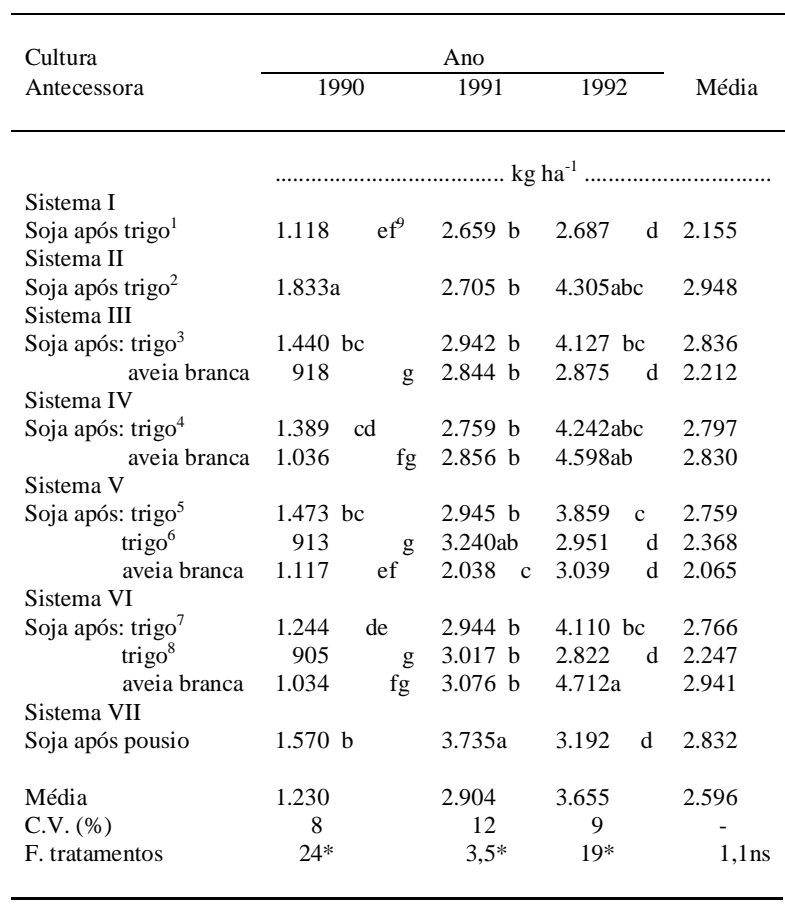

${ }^{1}$ Monocultura de trigo. Sistema I.

${ }^{2}$ Trigo após ervilhaca até 1990, depois trigo/soja ervilhaca e milho. Sistema II.

${ }^{3}$ Trigo após aveia branca e ervilhaca. Sistema III.

${ }^{4}$ Trigo após girassol, aveia branca e ervilhaca. Sistema IV.

${ }^{5}$ Trigo após aveia branca, ervilhaca e trigo. Sistema V.

${ }^{6}$ Trigo após trigo, aveia branca e ervilhaca. Sistema V.

${ }^{7}$ Trigo após girassol, aveia branca, ervilhaca e trigo. Sistema VI.

${ }^{8}$ Trigo após trigo, girassol, aveia branca e ervilhaca. Sistema VI.

${ }^{9}$ Médias seguidas da mesma letra, na coluna, não diferem entre si em $5 \%$ de probabilidade de erro, pelo teste de Duncan.

ns: não significativo; *: nível de significância de $5 \%$ de probabilidade de erro.

antecessora (aveia branca, aveia preta e trigo) (Tabela 5). Entretanto, o mesmo fato não ocorreu para a média dos anos, em virtude dos maiores rendimentos de grãos de soja terem variado entre os tratamentos, de um ano para outro. Em 1994, a cultura de soja produziu, em média, $4.024 \mathrm{~kg} \mathrm{ha}^{-1}$ (Tabela 5). Esse valor foi o mais elevado em todo o período experimental.

Nesses três períodos de estudo, a interação ano x tipo de cultura antecessora foi significativa para o rendimento de grãos de soja. Resultados semelhantes foram obtidos por SANTOS et al. (1989) e por SANTOS \& REIS (1991).

A ocorrência de doenças de soja, que têm se acentuado nos últimos anos, como a podridão parda da haste-pph, causada por Phialophora gregata, e o cancro da haste-ch, causado por Diaporthe phaseolorum f. $\mathrm{sp}$. meridionalis (COSTAMILAN \& LHAMBY, 1994; REUNIÃO, 1997), fez com que a cultivar BR-4, usada de 1987 a
Tabela 5 - Efeitos de culturas antecessoras no rendimento de grãos de soja, cultivar BR 16, de 1993 a 1995. Passo Fundo, RS, 1999

\begin{tabular}{|c|c|c|c|c|}
\hline \multirow{2}{*}{$\begin{array}{l}\text { Cultura } \\
\text { Antecessora }\end{array}$} & \multicolumn{3}{|c|}{ Ano } & \multirow[b]{2}{*}{ Média } \\
\hline & 1993 & 1994 & 1995 & \\
\hline & & $\ldots \ldots \ldots . . . \mathrm{kg}$ & $\mathrm{ha}^{-1}$. & \\
\hline \multicolumn{5}{|l|}{ Sistema I } \\
\hline $\begin{array}{l}\text { Soja após trigo }{ }^{1} \\
\text { Sistema II }\end{array}$ & $1.821 \mathrm{c}^{9}$ & 3.902 & $3.228 \mathrm{abcde}$ & 2.984 \\
\hline $\begin{array}{l}\text { Soja após trigo }{ }^{2} \\
\text { Sistema III }\end{array}$ & $2.928 \mathrm{~b}$ & 4.227 & $3.475 \mathrm{abc}$ & 3.543 \\
\hline Soja após: trigo ${ }^{3}$ & $2.831 \mathrm{~b}$ & 3.876 & 3.434abcd & 3.380 \\
\hline aveia branca & $2.208 \quad \mathrm{c}$ & 3.944 & 3.080 cde & 3.077 \\
\hline \multicolumn{5}{|l|}{ Sistema IV } \\
\hline Soja após: trigo ${ }^{4}$ & $3.083 \mathrm{~b}$ & 4.258 & $3.573 \mathrm{ab}$ & 3.638 \\
\hline aveia preta & $2.106 \mathrm{c}$ & 4.243 & 3.166 bcde & 3.172 \\
\hline aveia branca & $3.627 \mathrm{a}$ & 3.810 & 3.307abcd & 3.581 \\
\hline \multicolumn{5}{|l|}{ Sistema V } \\
\hline Soja após: trigo ${ }^{5}$ & $2.765 \mathrm{~b}$ & 4.141 & $3.618 \mathrm{a}$ & 3.508 \\
\hline trigo $^{6}$ & $1.981 \mathrm{c}$ & 4.038 & $3.461 \mathrm{abcd}$ & 3.160 \\
\hline aveia branca & $1.890 \mathrm{c}$ & 3.785 & 3.350abcd & 3.008 \\
\hline \multicolumn{5}{|l|}{ Sistema VI } \\
\hline Soja após: trigo ${ }^{7}$ & $3.061 \mathrm{~b}$ & 4.441 & $3.565 \mathrm{ab}$ & 3.689 \\
\hline trigo $^{8}$ & $2.010 \mathrm{~b}$ & 3.712 & $3.572 \mathrm{ab}$ & 3.098 \\
\hline aveia preta & $2.057 \mathrm{c}$ & 3.910 & $3.042 \mathrm{de}$ & 3.003 \\
\hline aveia branca & $3.117 \mathrm{~b}$ & 4.070 & 3.384abcd & 3.524 \\
\hline Sistema VII & & & & \\
\hline Soja após pousio & $2.142 \mathrm{c}$ & 4.003 & 2.826 & 2.900 \\
\hline Média & 2.508 & 4.024 & 3.338 & 3.290 \\
\hline C.V. (\%) & 11 & 7 & 8 & - \\
\hline F. tratamentos & $13^{*}$ & $1,8 \mathrm{~ns}$ & $2,4 *$ & $2,1 \mathrm{~ns}$ \\
\hline
\end{tabular}

${ }^{1}$ Monocultura de trigo. Sistema I.

${ }^{2}$ Trigo após ervilhaca até 1990, depois trigo/soja, ervilhaca e milho. Sistema II.

${ }^{3}$ Trigo após aveia branca e ervilhaca. Sistema III.

${ }^{4}$ Trigo após aveia preta, aveia branca e ervilhaca. Sistema IV.

${ }^{5}$ Trigo após aveia branca, ervilhaca e trigo. Sistema V.

${ }^{6}$ Trigo após trigo, aveia branca e ervilhaca. Sistema V.

${ }^{7}$ Trigo após aveia preta, aveia branca, ervilhaca e trigo. Sistema VI.

${ }^{8}$ Trigo após trigo, aveia preta, aveia branca e ervilhaca. Sistema VI

${ }^{9}$ Médias seguidas da mesma letra, na coluna, não diferem entre si em 5\% de probabilidade de erro, pelo teste de Duncan.

ns: não significativo; *: nível de significância de $5 \%$ de probabilidade de erro.

1992, que era suscetível à pph, fosse substituída pela BR-16, resistente a essas moléstias. Deve ser levado em conta que, nos sistemas I, III, IV, V e VI, havia monocultura de soja por dois, três e quatro verões. Contudo, nesses nove anos, pela observação de campo, ocorreu incidência relativamente baixa de doenças da parte aérea, sem causar danos ao rendimento de grãos dessa leguminosa.

Por outro lado, segundo observações realizadas, na média do período de 1987 a 1989, a soja cultivada após milho, nos sistemas III, IV, V e VI, tendeu a produzir mais do que a soja cultivada após dois, três e quatro verões consecutivos. Nos trabalhos desenvolvidos por EDWARDS et al. (1988) e por RUEDELL (1995), a soja em rotação com milho produziu rendimentos de grãos mais elevados do que a monocultura dessa leguminosa. 


\section{CONCLUSÕES}

A soja cultivada após aveia branca, aveia preta e trigo pode ser incluída, sem prejuízo, nos diferentes sistemas de sucessão de culturas recomendados para a Região Sul do Brasil.

A soja cultivada após linho mostra menores valores para rendimento de grãos e estatura de plantas.

\section{REFERÊNCIAS BIBLIOGRÁFICAS}

BARKER, M.R., WÜNSCHE, W.A. Plantio direto no Rio Grande do Sul. Outlook Agriculture, Oxford, v.9, n.8, p.114$120,1977$.

CARUSO, R. Soja: uma caminhada sem fim. Campinas : Fundação Cargill, 1996. 95p.

COSTAMILAN, L.M., LHAMBY, J.C.B. Incidência de podridão parda da haste da soja em diferentes sistemas de rotação de culturas. In: REUNIÃO DE PESQUISA DE SOJA DA REGIÃO SUL, 22, 1994, Cruz Alta. Soja: Resultados de pesquisa 1993/1994... Passo Fundo : EMBRAPA-CNPT, 1994. p.63-65. 138 p.

DENARDIN, J.E, KOCHHANN, R.A. Requisitos para a implantação e a manutenção do sistema plantio direto. In: EMBRAPA. Centro Nacional de Pesquisa de Trigo (Passo Fundo, RS). Plantio direto no Brasil. Passo Fundo: EMBRAPA-CNPT / FUNDACEP FECOTRIGO / Fundação ABC / Aldeia Norte, 1993. p.19-27.

EDWARDS, J.H., THURLOW, D.L., EASON, J.T. Influence of tillage and crop rotation on yields of corn, soybean, and wheat. Agronomy Journal, Madison, v.80, n.1, p.76-80, 1988.

MUZILLI, O. Fertilidade do solo em plantio direto. In: FANCELli, A.L., TORRADO, P.V., MACHADO, J. Atualização em plantio direto. Campinas : Fundação Cargill, 1985. Cap.7, p.147-160.

REUNIÃO DE PESQUISA DE SOJA DA REGIÃO SUL, 25, 1997, Passo Fundo. Recomendações técnicas para a cultura de soja no Rio Grande do Sul e em Santa Catarina 1997/98... Passo Fundo : EMBRAPA-CNPT, 1997. 130p.

ROMAN, E.R. Effect of cover on the development of weeds. In: INTERNATIONAL WORKSHOP ON CONSERVATION TILLAGE SYSTEMS, 1990, Passo Fundo. Conservation tillage for subtropical areas... Passo Fundo: CIDA/EMBRAPA-CNPT, 1990. p.258-262. 265p.

ROMAN, E.R., VELLOSO, J.A.R. de O. Controle cultural, coberturas mortas e alelopatia em sistemas conservacionistas. In: EMBRAPA-Centro Nacional de Pesquisa de Trigo (Passo Fundo, RS). Plantio direto no Brasil. Passo Fundo: EMBRAPA-CNPT/ FUNDACEP FECOTRIGO/Fundação ABC/Aldeia Norte, 1993. p.77-84.

RUEDELL, J. Plantio direto na região de Cruz Alta. Cruz Alta: FUNDACEP FECOTRIGO, 1995. 134p.
SANTOS, H.P. dos, LHAMBY, J.C.B., SANDINI, I. Efeitos de culturas de inverno e de sistema de rotação de culturas sobre algumas características da soja. Pesquisa Agropecuária Brasileira, Brasília, v.32, n.11, p.1141-1146, nov, 1997.

SANTOS, H.P. dos, LHAMBY, J.C.B., WOBETO, C. Efeito de culturas de inverno em plantio direto sobre a soja cultivada em rotação de culturas. Pesquisa Agropecuária Brasileira, Brasília, v.33, n.3, p.289-295, 1998.

SANTOS, H.P. dos, PEREIRA, L.R., REIS, E.M. Rotação de culturas. XXIV. Efeitos das culturas de inverno sobre o rendimento de grãos e sobre algumas características agronômicas de plantas de soja, num período de cinco anos. In: REUNIÃO DE PESQUISA DE SOJA DA REGIÃO SUL, 17., 1989, Porto Alegre. Soja: Resultados de pesquisa 19881989... Passo Fundo : EMBRAPA-CNPT, 1989. p.100-115, 119 p.

SANTOS, H.P. dos, REIS, E.M. Efeitos de culturas de inverno sobre o rendimento de grãos e sobre a estatura de plantas da soja. Pesquisa Agropecuária Brasileira, Brasília, v.26, n.5, p.729-735, abr, 1991 .

SANTOS, H.P. dos, REIS, E.M. Rotação de culturas. XIX. Efeitos de culturas de inverno sobre o rendimento de grãos e sobre algumas características agronômicas da soja. Pesquisa Agropecuária Brasileira, Brasília, v.25, n.11, p.1637-1645, out,1990.

SANTOS, H.P. dos, REIS, E.M., DERPSCH, R. Rotação de culturas. In: EMBRAPA. Centro Nacional de Pesquisa de Trigo (Passo Fundo, RS). Plantio direto no Brasil. Passo Fundo : EMBRAPA-CNPT / FUNDACEP FECOTRIGO / Fundação ABC / Aldeia Norte, 1993. p.85-103.

SANTOS, H.P. dos, TONET, G.E.L. Efeito de sistemas de produção incluindo culturas produtoras de grãos e pastagens anuais de inverno e de verão no rendimento de grãos e em outras características agronômicas de soja, sob sistema plantio direto. In: EMBRAPA. Centro Nacional de Pesquisa de Trigo (Passo Fundo, RS). Soja: Resultados de pesquisa do Centro Nacional de Pesquisa de Trigo, 1996/97. Passo Fundo, 1997. p.88-93, 172p. (EMBRAPA-CNPT. Documentos, 35). Trabalho apresentado na XXV Reunião de Pesquisa de Soja da Região Sul, Passo Fundo, 1997.

SANTOS, H.P. dos, VIEIRA, S.A., PEREIRA, L.R., et al. Rotação de culturas. XVI. Efeito de sistemas de cultivo no rendimento de grãos e outras características agronômicas das plantas de soja. Pesquisa Agropecuária Brasileira, Brasília, v.26, n.9, p.1539-1549, set, 1991.

SOCIEDADE BRASILEIRA DE CIÊNCIA DO SOLO. Comissão de Fertilidade do Solo - RS/SC. Recomendações de adubação e de calagem para os estados do Rio Grande do Sul e Santa Catarina. 3.ed. Passo Fund o: SBCS, 1995. $223 p$.

WÜNSCHE, W.A, TOMASINI, R.G.A. O uso adequado do solo e seus reflexos na economia energética do país: potencial da semeadura direta. In: CONGRESSO BRASILEIRO DE ENERGIA, 1, 1978, Rio de Janeiro. Anais... Rio de Janeiro: Clube de Engenharia / UFRJ-COPPE, [1978]. v.B, p.684-693, 967 .

Ciência Rural, v. 31, n. 1, 2001. 